\title{
Research Progress in the Epidemiology of HIV/AIDS in China
}

\author{
$\mathrm{NaHe} \mathrm{H}^{\mathrm{l}, \#}$
}

\begin{abstract}
After thirty-two years since the first domestic outbreak of human immunodeficiency virus (HIV)/ acquired immune deficiency syndrome (AIDS) among injection drug users (IDUs) and almost two decades of comprehensive response efforts by the Chinese government, HIV/AIDS remains a major public health problem. The increasing burden of HIV/AIDS and comorbidities, the emergence of new HIV subtypes and/or circulating recombinant forms and drug mutations, the changing transmission networks, and the urgency of immediate antiretroviral therapy initiation upon an HIV diagnosis are increasingly challenging and altogether likely to have significant impact on the HIV epidemic in China. Upon the call for the global AIDS response to end AIDS by 2030, China needs to develop an innovative and pragmatic roadmap to address these challenges. This review is intended to provide a succinct overview of what China has done in efforts to achieve the global goal of ending AIDS by 2030 and the recently proposed "95-95-9595” target (95\% combination prevention, 95\% detection, $95 \%$ treatment, $95 \%$ viral suppression), and to summarize the most recent progresses in the epidemiological research of HIV/AIDS in China with the aim of providing insights on the next generation of HIV control and prevention approaches and to shed light on upgrading the national strategy to end AIDS in this country.
\end{abstract}

\section{INTRODUCTION}

As the global AIDS response shifts to end AIDS by 2030 upon a call from the new United Nations General Assembly Political Declaration, the Chinese effort to end AIDS is entering a new era. After thirtytwo years since the first domestic outbreak of human immunodeficiency virus (HIV)/acquired immune deficiency syndrome (AIDS) among injection drug users (IDUs) and almost two decades of well-funded and comprehensive response efforts by the Chinese government, HIV/AIDS remains a major public health problem and a major cause of deaths in China. At the end of 2020, there were 1.053 million people living with HIV (PLWH) and 351,000 cumulative reported deaths in China (1). The proportion of heterosexual and homosexual transmission increased from $48.3 \%$ and $9.1 \%$ in 2009 to $74.2 \%$ and $23.3 \%$ in 2020 , respectively, whereas the proportion of HIV transmission by IDU declined substantially from $25.2 \%$ in 2009 to $<2.5 \%$ in 2020 . The standardized mortality of HIV/AIDS in China rose dramatically from 0.33 per 100,000 people in 1990 to 2.50 per 100,000 people in 2016 (2). The changing epidemiological profile and increasing burden of morbidities and mortalities, together with the emergence of new HIV subtypes and/or circulating recombinant forms (CRFs) and drug mutations, the changing transmission networks, and the urgency of immediate antiretroviral therapy (ART) upon HIV diagnosis are emerging challenges and threats and altogether likely to have significant impact on the HIV epidemic in China. We herein briefly review and summarize the most recent progresses in the epidemiological research of HIV/AIDS in China with an aim to shed light on upgrading the national strategy to end AIDS in this country.

\section{COMBINATION PREVENTION}

\section{HIV Risks and Prevention in MSM}

Men who have sex with men (MSM) are the highest-risk group for HIV infection and present an increasing public health challenge in China. Dong et al. estimated the national prevalence of HIV among MSM through a systematic analysis of data extracted from 355 studies (571,328 individuals) covering 59 cities from 30 provincial-level administrative divisions (PLADs) of China (3). The overall national prevalence of HIV among MSM from 2001 to 2018 was estimated to be $5.7 \%$ [95\% confidence interval (CI): $5.4 \%-6.1 \%$, with the highest in those aged 50 years or older (19.3\%). HIV was highly prevalent among those with illiteracy $(16.8 \%)$, those in the southwest 
(10.7\%), and those seeking partners in bathhouses/saunas (13.4\%). The HIV incidence among MSM was around 5.0 per 100 person-years (PY) (4), varying from 3.5 to $>10.0$ per $100 \mathrm{PY}(5-9)$.

Some innovative interventions, including electronic or internet-based technologies, crowd-sourcing, preexposure prophylaxis ( $\mathrm{PrEP}$ ), and postexposure prophylaxis (PEP), have recently been evaluated among MSM (10-12). Yun et al. conducted a randomized controlled trial (RCT) showing that mobile phone interventions based on an HIV risk prediction tool is promising in promoting HIV testing and reducing high-risk behavior among MSM (13). The same group also demonstrated that an assisted partner notification (PN) strategy could increase uptake of HIV testing among sexual partners of recently diagnosed MSM (14). Tang et al. demonstrated that an innovative crowdsourcing approach was effective for developing and strengthening community-based HIV testing services for MSM (15). Integrating social media with the distribution of self-test kits also holds promise to increase HIV testing coverage and case identification among MSM (16).

The national pilot PrEP and PEP program was first launched in Tianjin Municipality in 2017, and expanded to 7 PLADs by 2019. However, less than one thousand were regularly taking PEP and even fewer taking PrEP. The awareness of and willingness to use PrEP and PEP among MSM was still extremely low $(17-18)$. The probable barriers were the high price of PrEP $(69.9 \%)$, the need to use condoms consistently $(52.7 \%)$, concerns about side effects $(39.8 \%)$, and concerns about effectiveness of prevention (22.6\%) (18). Adequate PrEP promotions should be implemented, especially on the internet and dating apps.

\section{HIV Risks and Prevention in Older Men}

Older men have been increasingly and disproportionally affected by HIV over the past decade in China (19-20). According to China National Center for AIDS/STD Control and Prevention (NCAIDS), the proportion of newly reported HIVpositive cases made by males aged 60 years or older increased from $7.41 \%$ in 2010 to $18.21 \%$ in 2020 (1). The majority of them were infected through heterosexual contact (21). A recent meta-analysis pooling 30 studies of older men that were mostly at high-risk or MSM conducted during 2010-2018 in 13 PLADs found that the pooled HIV prevalence in people aged over 50 years was $1.68 \%$ (95\% CI: $1.00 \%-2.79 \%)$, higher $(2.60 \%)$ in eastern China than in central and western China (0.16\% and $2.13 \%)$ (22).

Limited studies have been designed to examine new interventions for HIV among older adults. Only few studies have been conducted to explore the efficacy of internet-or-network-based measures such as crowdsourcing or mobile apps in promotion of safer sex or HIV testing among MSM including those older than 50 years (15). Given the increasing spread of HIV among them, more HIV intervention studies that are psychosocially tailored for older adults are called for.

\section{HIV Risks and Prevention in College Students}

Cai et al. characterized the newly reported HIV/AIDS cases in young students in China between 2010 and 2019 (23). A total of 23,307 HIV/AIDS cases were reported in young students, with an overall male to female ratio of $33.9: 1$ and a mean age of $(19.90 \pm 2.05)$ years. The new diagnosis rate showed decreasing trends [annual percentage change (APC) $=-17.0]$ in the age group 23-24 years but increasing trend in the age group 15-17 years from 2015 to 2019 (23). The transmission route was mainly homosexual contact for males and heterosexual contact for females. Male cases were mainly identified by voluntary counseling and testing (VCT) clinics, whereas female cases were mainly found in hospitals (24). Liang et al. showed that there was a huge gap between female university students' willingness and practice of accepting VCT, as only $2.16 \%$ of the participants have ever had HIV tests (24).

Promoting safer sex and awareness of HIV status among college students is a major challenge for HIV control in China. Jiang et al. implemented an anonymous vending machine-based urine selfcollection for HIV testing (USCT) program in colleges across China (25). From June 2016 to December 2019, 146 vending machines stocked with urine selfcollection kits were distributed on 73 college campuses across 11 PLADs. Among the total of 5,178 kits sold, $3,109(60 \%)$ samples were returned, 2,933 (94\%) were eligible for testing, and of them $2.3 \%$ were tested HIVpositive, indicating that USCT is a powerful complement to current interventions that target at-risk students and promote HIV testing. Furthermore, given the low acceptance of PrEP and PEP by college students (26), studies are warranted to address this challenge. 


\section{HIV Risks and Prevention in FSWs}

Zhang et al. recently summarized the national and regional levels of HIV prevalence among female sex workers (FSWs) based on reported rates in the literature from 2008 to 2018 (27). The overall national HIV prevalence was below $1 \%$, showing a sporadic pattern in most PLADs. However, in the PLADs of Yunnan and Guangxi, the median-reported prevalence rates were close to or slightly above $1 \%$ (27). Using BED-CEIA, the HIV incidence among FSWs in Sichuan Province was estimated to be $0.22 \%$ (95\% CI: $0.16 \%-0.28 \%$ ) during 2011 to 2015 (28). Unfortunately, an accurate depiction of the epidemic in this population was obscured due to the lack of data on incidence. Notably, a rise in illicit use of synthetic drugs and changing sexual practices may represent newer risk factors for HIV transmission among FSWs, and a coordinated risk reduction framework remains urgently needed to address the dual epidemics of drug use and sexually transmitted infections (STIs) (29).

National prevention programs for HIV prevention in FSWs have widely promoted male condoms as a primary and practical measure. Limited studies have examined the feasibility and efficacy of innovative prevention tools or strategies, such as female condoms, PrEP, and PEP, to prevent HIV among FSWs or male clients (30). Given the vulnerability of FSWs to HIV infection, more research to gain comprehensive understanding of HIV incidence, risk trends, and innovative intervention strategies is needed.

\section{HIV Risks and Prevention in Other Key \\ Populations}

ART adherence by the HIV-positive spouses could substantially reduce secondary HIV transmission within serodiscordant couples (31-32). The coverage of ART for serodiscordant couples has increased from $58.1 \%$ in 2011 to $96.6 \%$ in 2020, and correspondingly, the HIV seroconversion rate among HIV-negative spouses has decreased from $2.60 \%$ in 2011 to $0.34 \%$ in 2020 (1). There is no doubt that immediate ART coupled with condom use for newly diagnosed HIV-positive spouses continues to be the most efficient strategy for preventing the HIV secondary transmission between serodiscordant couples.

Methadone maintenance treatment (MMT) has significantly reduced new HIV infections among IDUs in China. At the end of 2020, there were 791 MMT clinics and 22 mobile vans providing on-site MMT across 29 PLADs where 91,000 patients were served (1). The HIV seroconversion rate has declined by fourteen-fold from approximately $1 \%$ in 2006 to $0.07 \%$ in 2020 . Needle exchange program for IDUs is also ongoing in 12 PLADs.

\section{HIV DETECTION}

Promoting HIV testing was an essential method to achieve the first $90 \%$ of the global "90-90-90" target (90\% detection, $90 \%$ treatment, $90 \%$ viral suppression) by 2020 , and the second $95 \%$ of the upgraded global "95-95-95-95" target (95\% combination prevention, 95\% detection, 95\% treatment, $95 \%$ viral suppression). The overall persontimes of HIV testing increased over four-fold from 55.6 million in 2009 to $>240$ million in 2020 (1). This goal was achieved by rigorous efforts in massive HIV screening and testing strategies in the past decade. For example, VCT has rapidly scaled up, from 6,077 VCT sites identifying $19,611 \mathrm{HIV}$ positives out of $1,679,654$ attendants in 2008 to 11,319 sites identifying $28,498 \mathrm{HIV}$ positives out of 2,832,985 attendants in 2020 (1). On the other hand, HIV testing in medical institutes has been largely promoted through opt-out testing for clinical patients. In 2020, approximately 188 million person-times were tested and 79,475 were tested positive for HIV (1). However, delayed diagnosis of HIV infection remains a major concern for this strategy. Recent studies investigated the feasibility of and effective ways to promote homebased HIV self-testing (HIVST) in key populations especially MSM in China. Yan et al. conducted a largescale longitudinal study among MSM who received the HIVST service based on a mobile app providing the "Mail-in rapid test reagent kit" in Harbin, Heilongjiang Province from July 2017 to June 2018 (33). Overall, $10 \%$ of the MSM adhered to HIVST every 100 days. Twenty HIV seroconversions were observed during one-year follow up (34). Those who adhered to HIV testing were more likely to improve condom use behaviors, but these results were not statistically significant. Zhang et al. found that providing free HIVST kits significantly increased testing frequency among Chinese MSM and further effectively enhanced partner HIV testing through distribution of kits within their sexual networks (33). From 2015 to 2020, the number of HIVST kits sold on internet increased from 1 million to over 5 million (35). Future research is needed to provide more insights into the development of internet-based and/or 
social/sexual network-based interventions for HIVST among key populations.

\section{MOLECULAR EPIDEMIOLOGY}

\section{HIV-1 Subtypes and Recombinant Forms}

The distribution of HIV-1 subtypes and CRFs was highly diverse and complex in China. Yuan et al. conducted a systematic review and meta-analysis to provide a comprehensive prevalence estimate of different HIV-1 subtypes in sexual transmission by 2016 in China (36). A total of 130 eligible studies were identified, including 18,752 successfully genotyped samples. The pooled prevalence of CRF01_AE, subtype B, CRF07_BC, CRF08_BC, and subtype C were $44.54 \%, 18.31 \%, 16.45 \%, 2.55 \%$, and $0.37 \%$, respectively. HIV-1 subtype distribution varied significantly between regions. Recently, Wang et al. analyzed all Chinese pol region (2,253-3,252) sequences in the HIV Database to evaluate potential new CRFs in China (37). They found that CRF01_AE was the most prevalent genetic form in China, accounting for $39.69 \%$ of all national infections, followed by CRF07_BC (20.47\%), subtype B (17.50\%), CRF08_BC (6.60\%), subtype C (6.28\%), CRF55_01B (2.06\%), and other CRFs (1.77\%). The unique recombinant forms (URFs) were responsible for $5.31 \%$ of all infections nationwide. Among URFs, genomes comprising $\mathrm{BC}, 01 \mathrm{BC}, 01 \mathrm{~B}$, and $01 \mathrm{C}$ were dominant. Song et al. demonstrated that the HIV-1 phenotype and pathogenicity can be determined at the phylogenetic cluster level in the same subtype, highlighting the importance of monitoring the genetic evolution and phenotypic shift of HIV-1 to provide early warning of the appearance of more pathogenic strains (38).

\section{HIV Drug Resistance}

High prevalence of HIV drug resistance (HIVDR) would restrict therapy options, compromise the effect of current therapy regimens, and increase the risk of treatment failure. Zuo et al. systematically reviewed and assembled 218 datasets from 170 studies between January 2001 and March 2019, covering 21,451 ARTnaive and 30,475 ART-treated PLWH in China (39). The pooled prevalence of transmitted drug resistance (TDR) was $3.0 \%$, including $0.7 \%, 1.4 \%$, and $0.5 \%$ resistance for nucleoside and nucleotide reverse transcriptase inhibitors (NRTIs), non-nucleoside reverse-transcriptase inhibitors (NNRTIs), and protease inhibitor (PIs), respectively. TDR in the country overall has risen since 2012, and this rise was driven mainly by NNRTI resistance. Also, 1 NRTIassociated (M184V/I) and 3 NNRTI-associated (K103N/S, Y181C/I and G190A/S) mutations had high percentages in ART-naive and ART-treated individuals, and these mutations conferred high-level resistance to 3TC, EFV, and/or NVP (39).

HIVDR or mutations to PIs and other antiretroviral drugs (ARV) were also emerging. Yang et al. investigated the prevalence of integrase strand transfer inhibitors (INSTI)-associated resistance of HIV-1 strains in Henan Province during 2018-2020 (40). The prevalence of INSTI resistance was $1.2 \%$ overall, $0.63 \%$ for ART-naive patients, $2.05 \%$ for ART-treated patients with $14.63 \%$ for INSTI-treated and $0.76 \%$ for INSTI-naive patients. In a study of HIV-1 gp41 genetic diversity and enfuvirtide (ENF/T-20) drug resistance-associated mutations (DRMs) among enfuvirtide-naive patients in southern China, known DRMs were detected in $27.5 \%$ of ENF treatmentnaive patients, which have been proved to elevate resistance to ENF (41). Undoubtedly, HIVDR or DRMs will continue to evolve in an increasing trend which warrants enhanced surveillance and monitoring.

\section{HIV Molecular Transmission Networks}

In recent years, molecular transmission networks based on evolutionary theory and sequence analysis have been widely used in research on HIV transmission dynamics and for precise interventions for high-risk populations. Ma et al. conducted a study of PLWH who were sexually transmitted in Liaoning Province from 2003 to 2019 (42). They found that the molecular transmission networks formed by CRF01_AE, CRF07_BC, and B did not have interconnections. A molecular epidemiological study of HIV-1 among newly diagnosed MSM in 2017 in Jiangsu Province found that $182(23.7 \%)$ of 767 sequences were included in the HIV-1 transmission networks, forming 79 clusters with 4 clusters identified as fast-growing (43). Transmission among young MSM within networks was greater than the other age groups; thus, they could be essential in the control of the HIV epidemic in Jiangsu Province. Li et al. constructed genetic transmission networks of CRF08_BC based on its pol sequences, derived from the National HIV Molecular Epidemiology Survey (44). Of the 1,829 subjects, 639 (34.9\%) were clustered in 151 transmission networks. The most crossover links were found between heterosexual 
women and IDUs, with $30.9 \%$ heterosexual women linked to IDUs. These new findings underscored the importance of constructing molecular transmission networks and conducting long-term molecular monitoring, in addition to constructing behavioral networks and contact tracing (45) to further inform targeted measures for precise HIV prevention and control.

\section{ANTIRETROVIRAL THERAPY AND VIRAL SUPPRESSION}

Presently, the 4th edition of the China's National Guidelines for Free ART serves as the standard national reference, with continuous updates in regimens, enrollment criteria for ART, monitoring for CD4 counts, and HIV viral load and adverse effects of ARV. At the end of 2020, 978,138 (92.9\%) out of the total of 1.053 million PLWH in China were receiving ART, $96.1 \%$ of those on ART were able to achieve viral suppression (1). To further address the challenges in maintenance of a sustainable national ART program and a continuum of HIV care, including implementation of the test-and-immediately-treat policy and provision of care for individualized health needs of the patients (46-47), China is examining various service models for treatment and care. For example, the previous CDC-led AIDS treatment program and mode of management had been transferred to the hospital-based model years ago, which had proved to be effective and successful (48). Most recently, as the body of PLWH continuously increases, a community-based model for patient management is being examined to ameliorate work overload suffered in the hospital-based model.

\section{BURDEN OF HIV/AIDS MORBIDITY AND MORTALITY}

With a secondary analysis of the Global Burden of Diseases, Injuries, and Risk Factors Study 2017 data, Liu et al. observed that the HIV prevalence in China increased from 1990 to 2009 with an annual percent change (APC) of 10.7, and then remained stable from 2009 to 2017 (APC: 0.7) (49). A significant increase in HIV incidence was also observed for 1990 to 2005 (APC: 13.0) and then a significant decrease was detected for 2005 to 2017 (APC: -6.5). However, the AIDS-related mortality has increased sharply for 1990 to 2004 (APC: 10.3) and for 2013 to 2017 (APC:
15.3), although it stabilized for 2004 to 2013 (APC: 1.3) (49).

Morbidity and mortality of non-AIDS-defining diseases (NADs) have become the increasing burden of PLWH with long-term ART (50-57). Wang et al. carried out an evaluation of the burden, risk factors, and prognosis of serious non-AIDS-defining events (NADEs) among ART-naive AIDS patients admitted to a tertiary hospital between 2009 and 2018 in China (58). Among 1,309 patients, 143 (10.9\%) had at least one serious NADEs, including 49 (3.8\%) with cerebrovascular diseases, $37(2.8 \%)$ with non-AIDSdefining cancers, 28 (2.1\%) with chronic kidney diseases, $26(2.0 \%)$ with cardiovascular diseases (CVD), and $18(1.4 \%)$ with liver cirrhosis. Liu et al. also quantified the contribution of modifiable risk factors to NADs including CVD, end-stage liver disease (ESLD), advanced renal disease (ARD), and non-AIDS-defining cancers (NADCs) among 8,301 PLWHs starting ART at the Third People's Hospital of Shenzhen (China) from 2010 to 2017 (59). Incidence of CVD (362 per 100,000 PY) was the highest among outcomes, followed by that of ARD (270 per 100,000 PY), ESLD (213 per 100,000 PY), and NADC (152 per 100,000 PY). The contribution of traditional risk factors such as smoking, hypertension, and diabetes for these NADs far outweighed the HIV-related risk factors. An earlier cross-sectional study found that a third of PLWH had metabolic associated fatty liver disease, formerly named non-alcoholic fatty liver disease $(60)$. Individual-level interventions and population-level policymaking is needed to prevent NADs in long-term management of HIV infection in China.

\section{SYSTEMS EPIDEMIOLOGY OF HIV/AIDS}

Despite viral suppression by ART, HIV infection is associated with ongoing activation of the immune system and persistent inflammation (61), which are key driving forces in the loss of CD4+ $\mathrm{T}$ cells, progression to AIDS, and development of non-HIV-related but aging-related chronic complications (61). An early loss of gut mucosal integrity, the following microbial translocation, and other co-infections are all factors contributing to the ongoing immune activation and sustained inflammation (62). Genetic factors also play important roles in development of various noncommunicable chronic diseases (NCDs) in HIV 
infection. Zhao et al. demonstrated that the Asianspecific mitochondrial DNA haplogroups G and N9 may confer higher risk for the development of multiple sclerosis (MS) in PLWH in China (63).

Very recently, Ding et al. conducted a case-control study using untargeted metabolomics to characterize the key metabolites and metabolic pathways associated with HIV infection and multiple NCDs, focusing on identifying the common metabolic pathways underlying them (64). They found that PLWH presented widespread alterations in cellular metabolism versus HIV-negative individuals, and glycerophospholipid metabolism emerged as the potential common metabolic pathway underlying NCDs in treated HIV infection; followed by d-glutamine and d-glutamate, and alanine, aspartate and glutamate metabolism. The same group also performed 16S rRNA gene sequencing and untargeted metabolomics on fecal samples of PLWH with or without neurocognitive impairment (NCI). The results show that the decreased abundance of butyrate-producing bacteria, the increased abundance of Klebsiella, and the associated metabolites were associated with NCI in PLWH (65).

Further systems epidemiological research combining epidemiological data with system biology is needed to confirm these findings and to identify new mechanisms of aging-related NCDs comorbid with HIV infection using longitudinal multi-omics in China.

\section{HIV/AIDS DURING THE COVID-19 EPIDEMIC}

The coronavirus disease 2019 (COVID-19) pandemic has posed a serious threat to prevention, treatment, and healthcare services for HIV. From January 1 to April 16, 2020, $35(0.58 \%)$ of 6,001 PLWH experienced COVID-19 in Wuhan city, and 197 (3.3\%) had discontinued ART despite tremendous supportive efforts from both governmental and nongovernmental organizations (66). In Jiangsu Province, the HIV testing rates decreased by $49.0 \%(919,938)$ in the first three months of implementing COVID-19 measures (67). Of an estimated 1,555 new HIV diagnoses expected in the same period, only $63.0 \%$ new diagnoses were recorded (67). Links to HIV healthcare services including CD4 testing and ART were also seriously affected (67). Alternative or substitute ways to access healthcare for HIV during the COVID-19 epidemic might be considered. For example, Jiang et al. found that more MSM self-tested for $\operatorname{HIV}(52.1 \%$ vs. $41.6 \%)$ but fewer MSM used facility-based HIV testing ( $42.9 \%$ vs. $54.1 \%$ ) during COVID-19 measures compared to before COVID-19 measures (68). Furthermore, as compared to PLWH in other countries and the general population in most parts of the world, PLWH in China reported a relatively low willingness to receive the COVID-19 vaccination (69). The internet and social media as well as interpersonal communications may be major sources of influence on PLWH's perceptions and willingness to receive COVID-19 vaccination, which have important implications for immunization programs targeting PLWH.

\section{SUMMARY}

Despite aggressive and proactive national antiHIV/AIDS strategies and action plans, the number of newly identified HIV infections, diagnostic delays, HIV risks among key populations such as MSM and their sexual partners continues to rise in China. Innovative HIV interventions such as PrEP and PEP as well as intervention delivery utilizing information technology are increasingly examined and motivated, but lessons learned are less than encouraging. Without a deeper understanding of macrosocial epidemiology of HIV, scaling up HIV testing and treatment will be a necessary but insufficient strategy to end the epidemic. Aged- and culturally-appropriate health education, coupled with social prevention strategies, need to be a high priority among China's national HIV prevention priorities. Meanwhile, current facility-based HIV services should also be complimented by communityled services and including key populations as central to their responses, which requires much more implementation research.

With HIV infection as a chronic disease and NCDs as leading causes of death, efforts on screening, prevention, and management of comorbid NCDs are now warranted. It is also necessary to re-focus some of the research agendas and/or priorities in China. Systems epidemiological research integrating multiomics technologies could inform new biomarkers and biomedical targets for HIV prevention and treatment. Furthermore, PLWH are at increasingly and disproportionally higher risks of psychoactive stress and sleeping and mental health problems, so intervention programs to decrease perceived stress should be developed and implemented in China's resourcelimited mental health settings. Moreover, as the COVID-19 pandemic continues to spread around the 
world, it is particularly important to ensure PLWH have equal access to the utilization of health education, interventions, and services for COVID-19 as well as other diseases including HIV/AIDS.

Conflicts of Interest: No conflicts of interest.

Funding: Supported by Shanghai Municipal Health Commission (GWV-10.1-XK16), the National Natural Science Foundation of China (82173579, 81773485), and Yiwu Research Institute of Fudan University.

doi: $10.46234 / \mathrm{ccd} c w 2021.249$

\# Corresponding author: $\mathrm{Na} \mathrm{He,} \mathrm{nhe@fudan.edu.cn.}$

${ }^{1}$ Department of Epidemiology, School of Public Health, and The Key Laboratory of Public Health Safety of Ministry of Education; Shanghai Institute of Infectious Diseases and Biosecurity; and Yiwu Research Institute of Fudan University, Fudan University, Shanghai, China.

Submitted: November 14, 2021; Accepted: November 22, 2021

\section{REFERENCES}

1. National Center for AIDS \& STD Control and Prevention, The Chinese Center for Disease Control and Prevention (CDC). Annals of Information on Comprehensive Prevention and Treatment for AIDS, STD and Hepatitis C; 2020 July 9; Beijing, China.

2. Gao DS, Zou ZY, Dong B, Zhang WJ, Chen TQ, Cui WX, et al. Secular trends in HIV/AIDS mortality in China from 1990 to 2016: gender disparities. PLoS One 2019;14(7):e0219689. http://dx.doi.org/ 10.1371/journal.pone.0219689.

3. Dong MJ, Peng B, Liu ZF, Ye QN, Liu H, Lu XL, et al. The prevalence of HIV among MSM in China: a large-scale systematic analysis. BMC Infect Dis 2019;19(1):1000. http://dx.doi.org/10.1186/s12879-0194559-1.

4. Feng YB, Bu K, Li M, Zhang XY, Jin SS, Wang L. Meta-analysis of HIV infection incidence and risk factors among men who have sex with men in China. Chin J Epidemiol 2015;36(7):752 - 8. http://dx.doi. org/10.3760/cma.j.issn.0254-6450.2015.07.019. (In Chinese).

5. Cui Y, Guo W, Li D, Wang L, Shi CX, Brookmeyer R, et al. Estimating HIV incidence among key affected populations in China from serial cross-sectional surveys in 2010-2014. J Int AIDS Soc 2016;19(1):20609. http://dx.doi.org/10.7448/IAS.19.1.20609.

6. Chen Q, Sun YM, Sun WD, Hao MQ, Li GY, Su XL, et al. Trends of HIV incidence and prevalence among men who have sex with men in Beijing, China: nine consecutive cross-sectional surveys, 2008-2016. PLoS One 2018;13(8):e0201953. http://dx.doi.org/10.1371/journal. pone. 0201953 .

7. Han M, Pan PL, Wu GH, Zhou C, Yao Y, Luo J, et al. Estimating HIV incidence rates among MSM in an urban area of Chongqing using three approaches. Biomed Environ Sci 2017;30(12):913 - 6. http://dx.doi. org/10.3967/bes2017.122.

8. Zhang J, Xu JJ, Song W, Pan S, Chu ZX, Hu QH, et al. HIV incidence and care linkage among MSM first-time-testers in Shenyang, China, 2012-2014. AIDS Behav 2018;22(3):711 - 21. http://dx.doi.org/10. 1007/s10461-017-1840-4.

9. Yang H, Ye L, Su L, Liu Y, Xiao L, Hu Y, et al. An analysis on incidence of HIV-1 epidemics among men who have sex with men in Sichuan Province during 2011-2015. Chin J Prev Med 2019;53(3):327-9. http://med.wanfangdata.com.cn/Paper/Detail?dbid =WF_QK\&id=PeriodicalPaper_zhyfyx201903028. (In Chinese).

10. Cheng WB, Xu HF, Tang WM, Zhong F, Meng G, Han ZG, et al. Online HIV prevention intervention on condomless sex among men who have sex with men: a web-based randomized controlled trial. BMC Infect Dis 2019;19(1):644. http://dx.doi.org/10.1186/s12879-0194251-5.

11. Xu JJ, Huang XJ, Liu XC, Wang LM, Chen YK, Wang H, et al. Chinese experts' consensus on the use of HIV pre-exposure prophylaxis. Chin J AIDS STD 2020;26(11):1265-71. http://dx.doi.org/10. 13419/j.cnki.aids.2020.11.34. (In Chinese).

12. National Center for AIDS/STD Control and Prevention, China CDC. Technical Guideline for HIV Post-Exposure Prophylaxis (Trial). http:// ncaids.chinacdc.cn/zxzx/zxzx/202011/t20201116_222780.htm. [202011-16]

13. Yun K, Chu ZX, Zhang J, Geng WQ, Jiang YJ, Dong W, et al. Mobile phone intervention based on an HIV risk prediction tool for HIV prevention among men who have sex with men in China: randomized controlled trial. JMIR Mhealth Uhealth 2021;9(4):e19511. http://dx. doi.org/10.2196/19511.

14. Hu QH, Qian HZ, Li JM, Leuba SI, Chu ZX, Turner D, et al. Assisted partner notification and uptake of HIV testing among men who have sex with men: a randomized controlled trial in China. Lancet Reg Health West Pac 2021;12:100171. http://dx.doi.org/10.1016/j.lanwpc. 2021.100171.

15. Tang WM, Wei CY, Cao BL, Wu D, Li KT, Lu HD, et al. Crowdsourcing to expand HIV testing among men who have sex with men in China: a closed cohort stepped wedge cluster randomized controlled trial. PLoS Med 2018;15(8):e1002645. http://dx.doi.org/10. 1371/journal.pmed.1002645.

16. Wu D, Zhou Y, Yang N, Huang SZ, He X, Tucker J, et al. Social media-based secondary distribution of human immunodeficiency virus/syphilis self-testing among Chinese men who have sex with men. Clin Infect Dis 2021;73(7):e2251 - 7. http://dx.doi.org/10.1093/cid/ ciaa825.

17. Fu YS, Ashuro AA, Feng XX, Wang T, Zhang SC, Ye DQ, et al. Willingness to use HIV pre-exposure prophylaxis and associated factors among men who have sex with men in Liuzhou, China. AIDS Res Ther 2021;18(1):46. http://dx.doi.org/10.1186/s12981-021-00374-8.

18. Cui Z, Huang HJ, Zhang TT, Yu ZY, Zhang HL, Yao TT, et al. Low awareness of and willingness to use PrEP in the Chinese YMSM: an alert in YMSM HIV prevention. HIV Med 2021;22(3):185 - 93. http:/ /dx.doi.org/10.1111/hiv.12990.

19. Wang LY, Qin QQ, Ge L, Ding ZW, Cai C, Guo W, et al. Characteristics of HIV infections among over 50-year-olds population in China. Chin J Epidemiol 2016;37(2):222 - 6. http://dx.doi.org/10. 3760/cma.j.issn.0254-6450.2016.02.015. (In Chinese).

20. Chen HH, Wu XH, Chen L, Lu HX, Tang ZZ, Shen ZY, et al. Rapidly spreading human immunodeficiency virus epidemic among older males and associated factors: a large-scale prospective cohort study in rural Southwest China. Sex Transm Dis 2019;46(4):234 - 9. http://dx.doi. org/10.1097/OLQ.0000000000000957.

21. Wang CP, Guo Q, Han ZR, Chen DY. Awareness rate of HIV/AIDS core knowledge among the elderly: a meta-analysis. Chin J AIDS STD 2019;25(2):148 - 52. http://dx.doi.org/10.13419/j.cnki.aids.2019.02. 10. (In Chinese).

22. Zhang HX, Han MJ, Zhou Y, Xiu XF, Xu F, Wang L. HIV infection rate in people aged 50 years and older in China: a Meta-analysis. Chin J Epidemiol 2020;41(1):96 - 102. http://dx.doi.org/10.3760/cma.j.issn. 0254-6450.2020.01.018. (In Chinese).

23. Cai C, Tang H, Chen F, Li D, Lyu P. Characteristics and trends of newly reported HIV infection in young students in China, 2010-2019. Chin J Epidemiol 2020;41(9):1455 - 9. http://dx.doi.org/10.3760/ cma.j.cn112338-20200417-00592. (In Chinese).

24. Liang HX, Tang K, Cao WZ, Guo YP, Jiao Y, Zhu WY, et al. Factors influencing the acceptability of HIV/AIDS voluntary counselling and testing: a quantitative study of 41336 female university students in China. Sex Health 2021;18(1):119 - 21. http://dx.doi.org/10.1071/ SH20038.

25. Lv Y, Li GQ, Hu MG, Xu CD, Lu HY, Chen L, et al. Anonymous linkage between college students and Human Immunodeficiency Virus (HIV) facilities: systematic evaluation of urine self-collection for HIV 
testing initiative in China. Clin Infect Dis 2021;73(5):e1108 - 15. http: //dx.doi.org/10.1093/cid/ciaa1816.

26. Liu TT, Wang X, Li AX, Ye JZ, Shan D, Zhang G, et al. Service acceptance of HIV non-occupational post-exposure prophylaxis(nPEP) among college students: a cross-sectional study in China. BMC Public Health 2021;21(1):1220. http://dx.doi.org/10.1186/s12889-02111286-7.

27. Zhang HX, Hsieh E, Wang L, Liao SS. HIV/AIDS among female sex workers in China: epidemiology and recent prevention strategies. Curr HIV/AIDS Rep 2020;17(2):151 - 60. http://dx.doi.org/10.1007/ s11904-019-00477-y.

28. Yang H, Su L, Ye L, Xiao L, Hu Y, Shen MG, et al. Incidence rates of HIV-1 epidemics among 4 high risk groups in Sichuan province during 2011-2015. Chin J Epidemiol 2017;38(12):1649 - 54. http://dx.doi. org/10.3760/cma.j.issn.0254-6450.2017.12.014. (In Chinese).

29. Li J, Gong XD, Yue XL, Jiang N. Dual epidemics of club drug use and sexually transmitted infections among Chinese female sex workers: new challenges to STI prevention. Biomed Res Int 2017;2017:2093421. http://dx.doi.org/10.1155/2017/2093421.

30. Wang L, Huai PC, Jiao KD, Liu YC, Hua YM, Liu XY, et al. Awareness of and barriers to using non-occupational post-exposure prophylaxis among male clients of female sex workers in two cities of China: a qualitative study. Sex Health 2021;18(3):239 - 47. http://dx. doi.org/10.1071/SH20203.

31. He N, Duan S, Ding YY, Rou KM, McGoogan JM, Jia MH, et al. Antiretroviral therapy reduces HIV transmission in discordant couples in rural Yunnan, China. PLoS One 2013;8(11):e77981. http://dx.doi. org/10.1371/journal.pone.0077981.

32. Jia ZW, Mao YR, Zhang FJ, Ruan YH, Ma Y, Li J, et al. Antiretroviral therapy to prevent HIV transmission in serodiscordant couples in China (2003-11): a national observational cohort study. Lancet 2013;382 (9899):1195 - 203. http://dx.doi.org/10.1016/S0140-6736(12)618984.

33. Zhang C, Koniak-Griffin D, Qian HZ, Goldsamt LA, Wang HH, Brecht ML, et al. Impact of providing free HIV self-testing kits on frequency of testing among men who have sex with men and their sexual partners in China: a randomized controlled trial. PLoS Med 2020;17(10):e1003365. http://dx.doi.org/10.1371/journal.pmed.1003 365.

34. Yan XY, Su HX, Zhang B, Li YJ, Zhang LL, Jia ZW. Adherence of HIV self-testing among men who have sex with men in China: longitudinal study. J Med Internet Res 2020;22(9):e19627. http://dx. doi.org/10.2196/19627.

35. Kumar N, Forastiere L, Janmohamed K, Yang F, Zhang TG, Sha YJ, et al. Improving HIV self-testing social network interventions: the role of sexual behavior disclosure among Chinese men who have sex with men. AIDS Behav 2021;25(6):1984 - 92. http://dx.doi.org/10.1007/s10461020-03128-1.

36. Yuan R, Cheng H, Chen LS, Zhang X, Wang B. Prevalence of different HIV-1 subtypes in sexual transmission in China: a systematic review and meta-analysis. Epidemiol Infect 2016;144(10):2144 - 53. http:// dx.doi.org/10.1017/S0950268816000212.

37. Wang XR, Zhang Y, Liu YJ, Li HP, Jia L, Han JW, et al. Phylogenetic analysis of sequences in the HIV database revealed multiple potential circulating recombinant forms in China. AIDS Res Hum Retroviruses 2021;37(9):694 - 705. http://dx.doi.org/10.1089/aid.2020.0190.

38. Song HS, Ou WD, Feng Y, Zhang JL, Li F, Hu J, et al. Disparate impact on CD4 $\mathrm{T}$ cell count by two distinct HIV-1 phylogenetic clusters from the same clade. Proc Natl Acad Sci USA 2019;116(1):239 - 44. http://dx.doi.org/10.1073/pnas.1814714116.

39. Zuo LL, Liu K, Liu HL, Hu YH, Zhang ZJ, Qin JR, et al. Trend of HIV-1 drug resistance in China: a systematic review and meta-analysis of data accumulated over 17 years (2001-2017). EClinical Med 2020;18:100238. http://dx.doi.org/10.1016/j.eclinm.2019.100238.

40. Yang ZJ, Yang X, Deng X, Wei SG, Liu J, Ma JJ, et al. Prevalence of Integrase Strand Transfer Inhibitor (INSTIs) resistance mutations in Henan Province, China (2018-2020). Infection 2021 Jul 19. Online ahead of print. http://dx.doi.org/10.1007/s15010-021-01668-9.
41. Chang L, Zhao JP, Guo F, Ji HM, Zhang L, Jiang XY, et al. HIV-1 gp41 genetic diversity and enfuvirtide resistance-associated mutations among enfuvirtide-naive patients in southern China. Virus Res 2021;292:198215. http://dx.doi.org/10.1016/j.virusres.2020.198215.

42. Ma N, Chen XH, Zhao Y, Kang X, Pan S, Yao WQ. HIV-1 molecular transmission network among sexually transmitted populations in Liaoning Province, China. Medicine 2021;100(28):e26640. http://dx. doi.org/10.1097/MD.0000000000026640.

43. Yin YQ, Zhou Y, Lu J, Liu XY, Shi LG, Fu GF, et al. Molecular epidemiology of HIV-1 in Jiangsu province, Southeast China: genotypes and HIV-1 transmission networks among newly diagnosed men having sex with men in 2017. AIDS Res Hum Retroviruses 2021;37(1):62 - 9. http://dx.doi.org/10.1089/aid.2020.0165.

44. Li K, Liu ML, Chen HH, Li JJ, Liang YL, Feng Y, et al. Using molecular transmission networks to understand the epidemic characteristics of HIV-1 CRF08_BC across China. Emerg Microbes Infect 2021;10(1):497 - 506. http://dx.doi.org/10.1080/22221751. 2021.1899056.

45. Lin HJ, He N, Zhou SJ, Ding YY, Qiu DH, Zhang TJ, et al. Behavioral and molecular tracing of risky sexual contacts in a sample of Chinese HIV-infected men who have sex with men. Am J Epidemiol 2013;177(4):343 - 50. http://dx.doi.org/10.1093/aje/kws256.

46. Ma Y, Dou ZH, Guo W, Mao YR, Zhang FJ, McGoogan JM, et al. The human immunodeficiency virus care continuum in China: 19852015. Clin Infect Dis 2018;66(6):833 - 9. http://dx.doi.org/10.1093/ $\mathrm{cid} / \mathrm{cix} 911$.

47. Zhao Y, Wu ZY, McGoogan JM, Shi CX, Li AH, Dou ZH, et al. Immediate antiretroviral therapy decreases mortality among patients with high CD4 counts in China: a nationwide, retrospective cohort study. Clin Infect Dis 2018;66(5):727 - 34. http://dx.doi.org/10.1093/ $\mathrm{cid} / \mathrm{cix} 878$.

48. Dou ZH, Zhang FJ, Zhao Y, Jin CR, Zhao DC, Gan XM, et al. Progress on China's national free antiretroviral therapy strategy in 2002 2014. Chin J Epidemiol 2015;36(12):1345 - 50. http://dx.doi.org/10. 3760/cma.j.issn.0254-6450.2015.12.005. (In Chinese).

49. Liu XJ, McGoogan JM, Wu ZY. Human immunodeficiency virus/acquired immunodeficiency syndrome prevalence, incidence, and mortality in China, 1990 to 2017: a secondary analysis of the Global Burden of Disease Study 2017 data. Chin Med J 2021;134(10):1175 80. http://dx.doi.org/10.1097/CM9.0000000000001447.

50. Zhu WM, Mao YR, Tang HL, McGoogan JM, Zhang ZF, Detels R, et al. Spectrum of malignancies among the population of adults living with HIV infection in China: a nationwide follow-up study, 20082011. PLoS One 2019;14(7):e0219766. http://dx.doi.org/10.1371/ journal.pone.0219766.

51. Lin HJ, Ding YY, Ning CX, Qiao XT, Chen XC, Chen XX, et al. Agespecific associations between HIV Infection and carotid artery intimamedia thickness in China: a cross-sectional evaluation of baseline data from the CHART Cohort. Lancet HIV 2019;6(12):e860 - 8. http://dx. doi.org/10.1016/S2352-3018(19)30263-2.

52. Schouten J, Wit FW, Stolte IG, Kootstra NA, van der Valk M, Geerlings SE, et al. Cross-sectional comparison of the prevalence of ageassociated comorbidities and their risk factors between HIV-infected and uninfected individuals: the $\mathrm{AGE}_{\mathrm{h}} \mathrm{IV}$ cohort study. Clin Infect Dis 2014;59(12):1787 - 97. http://dx.doi.org/10.1093/cid/ciu701.

53. Ding Y, Duan S, Ye R, Yao S, Cao D, Yang Y, et al. Effects of aging, baseline renal function and stage of HIV infection on post-treatment changes in renal function among HIV-infected patients: a retrospective cohort study. HIV Med 2019;20(9):591 - 600. http://dx.doi.org/10. 1111/hiv. 12763.

54. Ye RH, Li J, Yao ST, Wang JB, Cao DD, Zhang YD, et al. Prevalence and related factors on diabetes among HIV/AIDS receiving antiretroviral therapy in Dehong Dai and Jingpo Autonomous Prefecture.. Chin J Epidemiol 2019;40(6):654 - 9. http://dx.doi.org/ 10.3760/cma.j.issn.0254-6450.2019.06.010 (In Chinese)..

55. Xu X, Lin H, Chen X, Zhu B, Shen W, Ning C, et al. Differences in hypertension and prehypertension among people living with and without HIV in China: role of HIV infection and antiretroviral therapy. 
HIV Med 2021;22(5):409 - 17. http://dx.doi.org/10.1111/hiv.13040. 56. Zhao TT, Wei B, Long JX, Tang XY, Zhou MX, Dang C. Cognitive disorders in HIV-infected and AIDS patients in Guangxi, China. J NeuroVirol 2015;21(1):32 - 42. http://dx.doi.org/10.1007/s13365014-0295-x.

57. Guo F, Song X, Li Y, Guan W, Pan W, Yu W, et al. Longitudinal change in bone mineral density among Chinese individuals with HIV after initiation of antiretroviral therapy. Osteoporos Int 2021;32(2):321 - 32. http://dx.doi.org/10.1007/s00198-020-05584-w.

58. Wang Y, Liang HY, Zhang L, Zhang Z, Wu L, Ni L, et al. The burden of serious non-AIDS-defining events among admitted cART-naive AIDS patients in China: an observational cohort study. PLoS One 2020;15(12):e0243773. http://dx.doi.org/10.1371/journal.pone.0243 773.

59. Liu JY, Hou YY, Sun LQ, Wang LF, He Y, Zhou Y, et al. High population-attributable fractions of traditional risk factors for nonAIDS-defining diseases among people living with HIV in China: a cohort study. Emerg Microbes Infect 2021;10(1):416 - 23. http://dx. doi.org/10.1080/22221751.2021.1894904.

60. Liu DP, Shen YZ, Zhang RF, Xun JN, Wang JR, Liu L, et al. Prevalence and risk factors of metabolic associated fatty liver disease among people living with HIV in China. J Gastroenterol Hepatol 2021;36(6):1670 - 8. http://dx.doi.org/10.1111/jgh.15320.

61. Deeks SG, Tracy R, Douek DC. Systemic effects of inflammation on health during chronic HIV infection. Immunity 2013;39(4):633 - 45 http://dx.doi.org/10.1016/j.immuni.2013.10.001.

62. Sun J, Su JW, Xie YR, Yin MT, Huang Y, Xu LJ, et al. Plasma IL-6/IL10 ratio and IL-8, LDH, and $\mathrm{HBDH}$ level predict the severity and the risk of death in AIDS patients with Pneumocystis pneumonia. J Immunol Res 2016;2016:1583951. http://dx.doi.org/10.1155/2016/ 1583951.

63. Zhao D, Ding YY, Lin HJ, Chen XX, Shen WW, Gao MY, et al.
Mitochondrial haplogroups N9 and G are associated with metabolic syndrome among human immunodeficiency virus-infected patients in China. AIDS Res Hum Retroviruses 2019;35(6):536 - 43. http://dx. doi.org/10.1089/aid.2018.0151.

64. Ding YY, Lin HJ, Chen XX, Zhu BW, Xu XH, Xu XY, et al. Comprehensive metabolomics profiling reveals common metabolic alterations underlying the four major non-communicable diseases in treated HIV infection. EBioMedicine 2021;71:103548. http://dx.doi. org/10.1016/j.ebiom.2021.103548.

65. Dong RH, Lin HJ, Chen XX, Shi RZ, Yuan SY, Li J, et al. Gut microbiota and fecal metabolites associated with neurocognitive impairment in HIV-infected population. Front Cell Infect Microbiol 2021;11:723840. http://dx.doi.org/10.3389/fcimb.2021.723840.

66. Huang J, Xie N, Hu X, Yan H, Ding J, Liu P, et al. Epidemiological, virological and serological features of coronavirus disease 2019 (COVID-19) cases in people living with human immunodeficiency virus in Wuhan City: a population-based cohort study. Clin Infect Dis 2021;73(7):e2086 - 94. http://dx.doi.org/10.1093/cid/ciaa1186.

67. Shi LG, Tang WM, Hu HY, Qiu T, Marley G, Liu XY, et al. The impact of COVID-19 pandemic on HIV care continuum in Jiangsu, China. BMC Infect Dis 2021;21(1):768. http://dx.doi.org/10.1186/ s12879-021-06490-0.

68. Jiang HB, Xie YW, Xiong Y, Zhou Y, Lin KH, Yan Y, et al. HIV selftesting partially filled the HIV testing gap among men who have sex with men in China during the COVID-19 pandemic: results from an online survey. J Int AIDS Soc 2021;24(5):e25737. http://dx.doi.org/10. 1002/JIA2.25737.

69. Huang XJ, Yu MH, Fu GF, Lan GH, Li LH, Yang JZ, et al. Willingness to receive COVID-19 vaccination among people living with HIV and AIDS in China: nationwide cross-sectional online survey. JMIR Public Health Surveill 2021;7(10):e31125. http://dx.doi.org/10. $2196 / 31125$

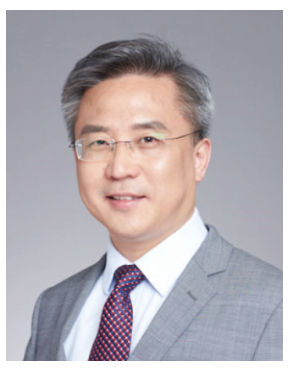

$\mathrm{Na} \mathrm{He}, \mathrm{MBBS}, \mathrm{MSc}, \mathrm{PhD}$

Professor of Epidemiology

Dean, School of Public Health

Fudan University, Shanghai, China 